\title{
Surface Improvement of Shafts by Turn-Assisted Deep Cold Rolling Process
}

\author{
Raghavendra Prabhu' ${ }^{1}$, S. S. Sharma ${ }^{1}$, Jagannath $\mathrm{K}^{1}$, Krishna Kumar ${ }^{1}$, S. M. Kulkarni ${ }^{2}$ \\ ${ }^{1}$ Faculty, Dept. of Mechanical \& Manufacturing Engineering, Manipal Institute of Technology, Manipal University, India \\ ${ }^{2}$ Faculty, Dept. of Mechanical Engineering, National Institute of Technology Karnataka, Surathkal, India
}

\begin{abstract}
It is well recognized that mechanical surface enhancement methods can significantly improve the characteristics of highly-stressed metallic components. Deep cold rolling is one of such technique which is particularly attractive since it is possible to generate, near the surface, deep compressive residual stresses and work hardened layers while retaining a relatively smooth surface finish. In this paper, the effect of turn-assisted deep cold rolling on AISI 4140 steel is examined, with emphasis on the residual stress state. Based on the X-ray diffraction measurements, it is found that turn-assisted deep cold rolling can be quite effective in retarding the initiation and initial propagation of fatigue cracks in AISI 4140 steel.
\end{abstract}

\section{Introduction}

The surface layer is determined by manufacturing processes, and mainly, by finishing processes. Machining is a modest alternative process for fabricating a wide range of mechanical components, such as gears, cams, shafts, axles and others. The process of machining steel is complex and the surface generated is influenced by several variables: steel properties (elastic and plastic deformations), tool material and geometry, vibration of cutting tool, cutting speed, feed, depth of cut, lubricant, etc. Besides, previous works have shown that in the machined surface of metals a damage region is produced that is different from the bulk of the material [1]. During machining, the surface layer is subjected to elastic-plastic deformation and heating, which result in structural changes, strain hardening and residual stresses. Fillets, grooves, notches, and holes are always present in most of the engineering components, and fatigue related cracks will originate from these sites where the local stress is highest. All stress concentrators in the component can never be eliminated; however the negative effects of stress concentrators can be reduced by different means, one of which is the compressive residual stress. Compressive residual stresses in the surface region of materials with high hardness increase the fatigue life and the fatigue limit during cyclic loading compared with the materials that are free of residual stresses [2]-[4]. Residual stresses are introduced in metallic components intentionally with shot peening/prestraining, or unintentionally with metal-forming processes such as forging, rolling, milling, and welding. These processes introduce residual stresses as a result of inhomogeneous plastic deformation due to mechanically or thermally induced loads [5,] [6]. Mechanical surface treatments, such as shot peening, laser shock peening and deep rolling efficiently enhance the fatigue performance of various metallic components. This enhancement results from induced macroscopic compressive residual stresses and work hardening at the surface and in near-surface regions inhibiting or retarding crack initiation and propagation resulting in fatigue performance enhancement. This paper focusses on carrying out deep cold rolling process in a cost-effective way using turnassisted deep cold rolling (TADCR) instead of special machines and tools. The TADCR involves conventional lathe with a follower rest and rolling attachments, to improve the fatigue life and surface properties of AISI 4140 steel.

The objective of this work is to investigate the effect of parameters in TADCR process on residual compressive stress. The effect of four parameters, namely, rolling force, ball diameter, initial roughness of the workpiece and number of passes are considered for investigation. The residual stresses are measured experimentally and are calculated using finite-element analysis. The increase in the measured residual stress was correlated with the results obtained from finite-element analysis.

\section{Material and process}

The workpiece material used in this study is AISI 4140 steel which is especially recommended for the manufacture of transmission shaft, gear shaft, crank shaft and also for a wide variety of automotive type applications [7]. The work pieces are received as bright cylindrical bars of $12 \mathrm{~mm}$ diameter. The chemical 
composition of AISI 4140 steel in mass $\%$ is as follows: $0.40 \mathrm{C}, 0.27 \mathrm{Si}, 0.66 \mathrm{Mn}, 0.055 \mathrm{P}, 0.046 \mathrm{~S}, 1.20 \mathrm{Cr}, 0.25 \mathrm{Mo}$, $0.16 \mathrm{Ni}$. The ultimate tensile strength and yield strength of the starting specimen at room temperature is $946 \mathrm{MPa}$ and $848 \mathrm{MPa}$ respectively. The average initial hardness of the material measured by MATSUZAWA Micro-Vickers hardness tester and is found to be about 225HV.The specimens are prepared as per the ASTM-E466 requirements to conduct fatigue tests. Figure 1 shows the dimensions of the specimen that is used for conducting the experiments. Specimens are turned to given diameter on a conventional lathe to render a surface roughness common in turning process.

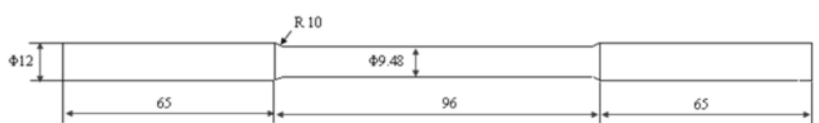

Figure 1. Workpiece geometry (mm)

The proposed TADCR set-up consists of a lathe (PSG type A 141) and an in-house designed tool and other accessories as shown in Fig. 2. A Kistler dynamometer mounted on the lathe tool post is used to measure the forces during the process. The specimen is held in a three jaw chuck at one end and supported by tail stock at the other end. The rolling force is adjusted through depth of penetration.

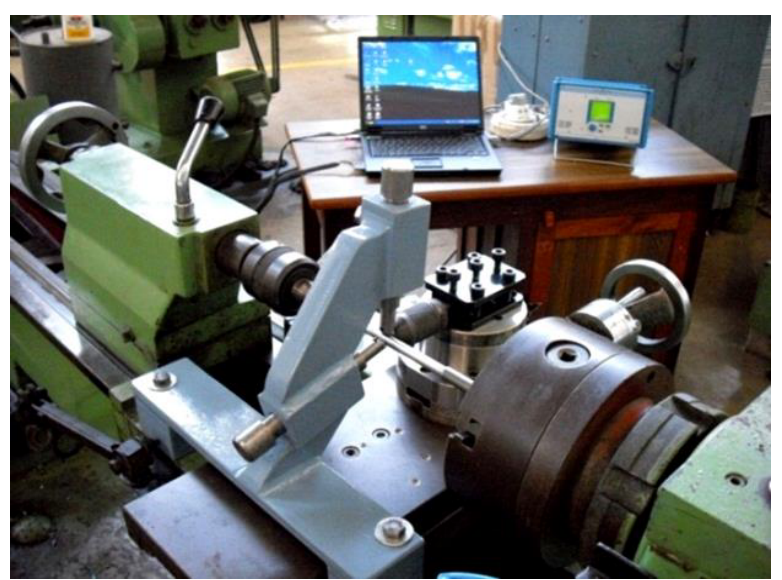

Figure 2. Experimental set-up of TADCR process

Table 1. Factors and levels for CCD

\begin{tabular}{|l|c|c|c|c|}
\hline Factor & Unit & Level 1 & Level 2 & Level 3 \\
\hline Ball Diameter & $\mathrm{mm}$ & 6 & 8 & 10 \\
\hline Rolling Force & $\mathrm{N}$ & 250 & 500 & 750 \\
\hline $\begin{array}{l}\text { Initial } \\
\text { Roughness }\end{array}$ & $\mu \mathrm{m}$ & 4.84 & 6.15 & 7.46 \\
\hline No. of Passes & & 1 & 2 & 3 \\
\hline
\end{tabular}

The forces are recorded using the DynoWare software. An experimental plan with Central Composite Design (CCD) is used to investigate the influence of four parameters, rolling force, ball diameter, initial roughness of the workpiece and number of passes on residual compressive stress. Each parameter is considered in three levels and three replicates are used for each design point in the CCD. The parameters, their levels and magnitudes are shown in Table 1. Residual compressive stress measurements are made by using a Rigaku X-ray diffractometer. Samples are cut out along the feed direction and microstructure of the stressed region is acquired by an optical microscope.

\section{Results and discussion}

\subsection{Finite element analysis of TADCR process}

In the last decades, a majority of the research was centered on the experimental determination of relationships for the surface finish and state of residual stress with the burnishing and deep cold rolling process parameters for specific applications. Afshin Manouchehrifar and Kianoush Alasvand [8] conducted a comprehensive 3D finite element dynamic analysis with considering spring back effect to simulate the deep rolling process. The results revealed that increase in overlap of the rolling tracks largely increases the magnitude of the residual stress filed created in target plate. Moreover, increase in the friction coefficient between roller and target plate results in decrease in magnitude of the residual stress filed. It is found that, increase in the force intensity results in increase magnitude of the maximum residual stress. The objective of this study is to establish an FEM model for TADCR process to study the effects of process parameters on residual stresses and to validate the simulation results with results obtained from TADCR experiments. In this study, 2D FEM models of TADCR process were developed. Turning and consequent deep cold rolling experiments were conducted in order to understand the process setup, to evaluate the surface improvement and to understand the influence of process parameters. The basic model allowed the study of the influence of process parameters, such as ball diameter, depth of penetration, initial roughness of work piece and number of tool passes, on residual stresses.

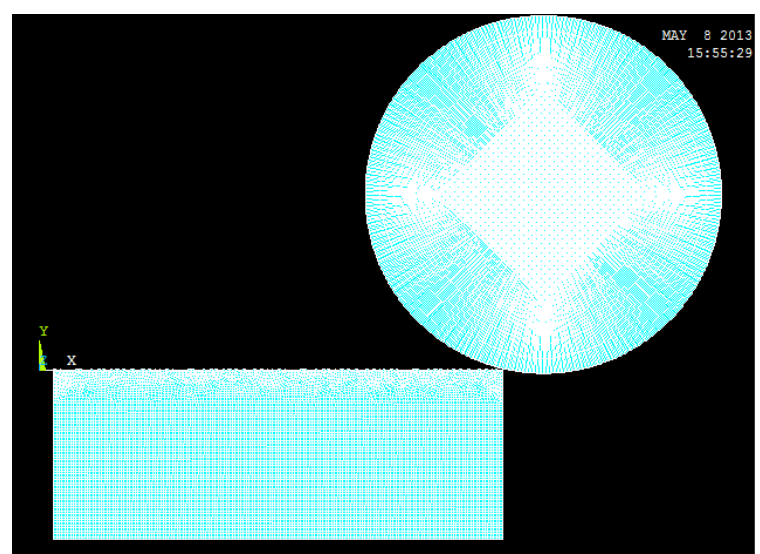

Figure 3. Finite element model for contact analysis

The FEA package ANSYS was used to generate a 2Dimensional contact model. The dimensions of the model are taken exactly same as the workpiece and tool dimensions. This is shown in Figure 3. The dimensions of the model are taken exactly equal to the workpiece and tool dimensions. 
Both the workpiece and ball were meshed with fournoded 2D solid 162 elements with 6 degrees of freedom at each node. The ball is modelled as a circle and it is given the nodal translation degree of freedom in " $x$ " direction. The workpiece boundary conditions restricted all the degrees of freedom of the three sides of the workpiece that were not in contact with the ball. Fig. 4 shows a basic diagram of the deep cold rolling 2D model with all the applied boundary conditions. The ball remains nondeformable when loads are applied, so in the finite element model a rigid material model is chosen and for the work piece kinematic plastic material model is chosen. The optimum value of deep cold rolling force determined experimentally is used in the Finite Element Analysis. The results of this analysis include the induced residual compressive stress. The applied deep cold rolling force is related to the depth of penetration, which in turn is related to the surface finish obtained and the residual stresses induced in the component. Thus depth of penetration plays an important role in the TADCR process. Surface roughness generated after the turning operation was used to model the surface roughness pattern which was further used to simulate the process.

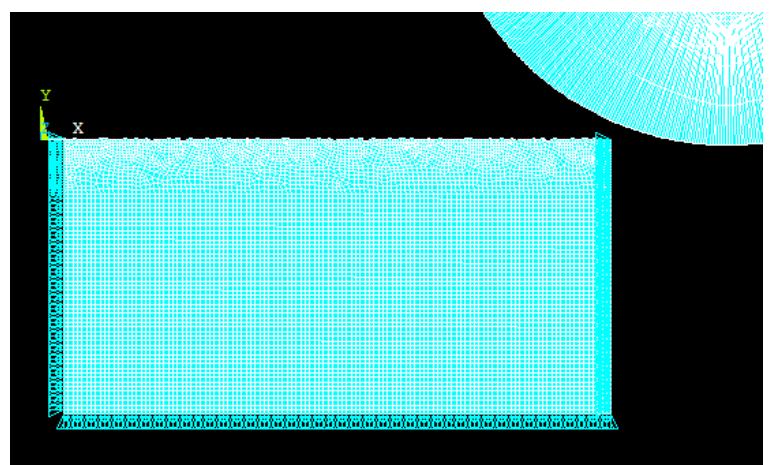

Figure 4. Mesh and boundary conditions of the workpiec0e in 2D simulation

The main effect of deep rolling is restricted to a thin layer below the surface $(0.2-0.4 \mathrm{~mm})$. A FE model that describes the effects on a small geometric volume on a thin layer below the ball was developed according to Fig. 5 . The mesh topology was zoomed with a higher density close to the surface. The model consists of 28315 2D solid 162 elements. Mesh was made finer near the surface of the work piece.

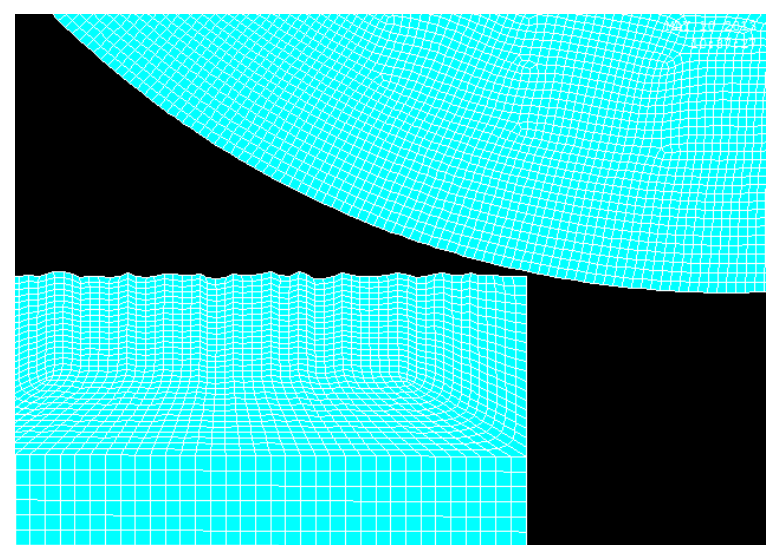

Figure 5. Finite element of deep cold rolling and element topology at surface

\subsection{Finite element model validation}

To obtain the stress distribution, a central area of the simulation is selected. The Finite Element results from elements just below the surface are analyzed and post processed. Figure 6 shows the effect of deep cold rolling on the simulated residual stress distribution. In fact, as the deep cold rolling force increased, higher residual stresses are obtained, and at a greater depth. Therefore, results show that when the objective of this surface treatment is the introduction of high residual stresses, the best option is to roll the surface with the maximum force; however this can lead to an increase of roughness and geometrical error.
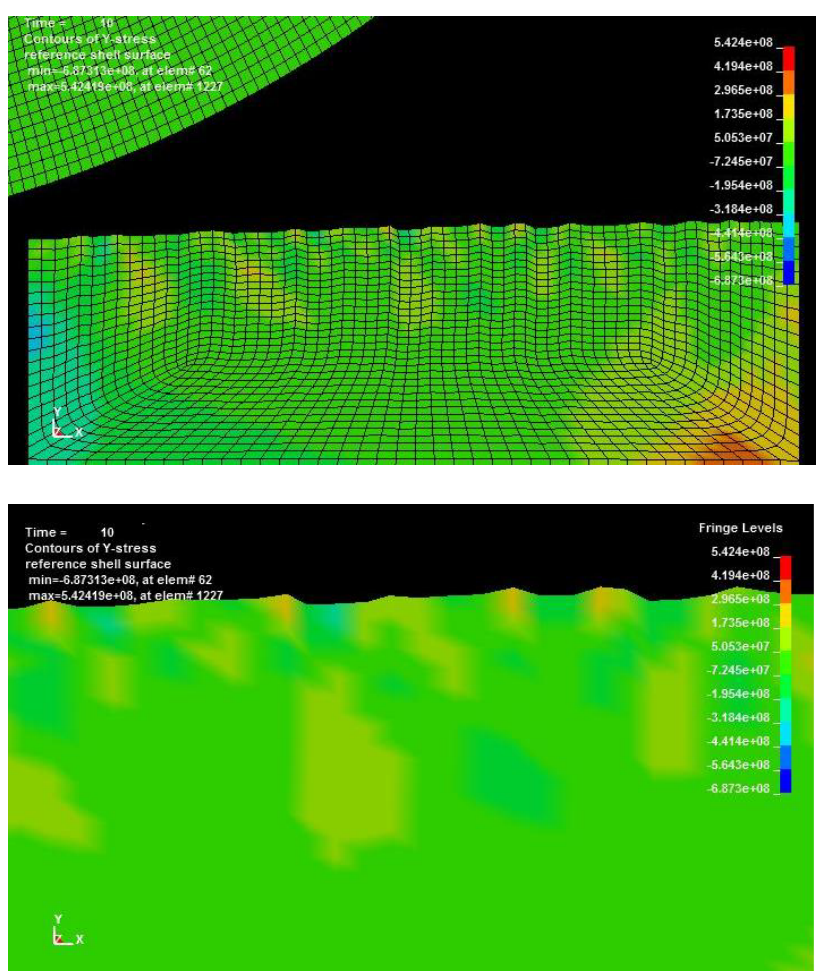

Figure 6. Analysis zone with residual stresses on the model

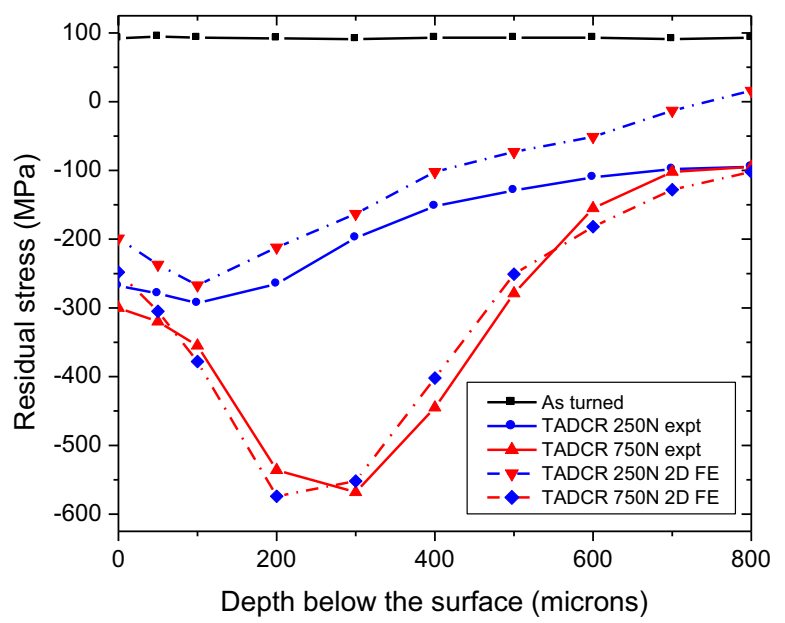

Figure 7. Residual stress evolution from simulations \& experiments

In order to verify the accuracy of the finite element simulation of turn-assisted deep cold rolling, the residual stress profile was compared with the experimentally 
obtained data and is shown in Fig. 7. As the figure indicates, the values obtained from FEA are quite closer to the experimentally determined values because the modelling of FEA includes surface-to-surface contact in $2 \mathrm{D}$ between the tool and workpiece, which represents the real phenomenon occurring in actual turn-assisted deep cold rolling process.

\section{Conclusions}

In this study, the effects of four process parameters ball diameter, rolling force, initial roughness of the workpiece and number of tool passes on the residual compressive stress of AISI 4140 steel are investigated. Rolling force has a major influence on residual stresses. The amount of plastic deformation in the workpiece increases with force and hence the magnitude of compressive residual stresses increase with increasing rolling force. Predictions of residual stress distributions beneath the turn-assisted deep cold rolled surface, with the 2D FEM model are in good agreement with the experimental measurements obtained using X-Ray diffractions. The maximum residual stress obtained by the 2D FE simulation differed by approximately $15 \%$ from the experimental data.

\section{References}

1. P. G. Benardos and G. C. Vosniakos: Predicting Surface Roughness in Machining: A review,
International Journal of Machine Tools \& Manufacture, 43, No. 8, p. 833-844, (2003).

2. L. Bertini and V. Fontanari: Fatigue Behavior of Induced Hardened Notched Components, International Journal of Fatigue, 21, p. 611-617 (1999).

3. H. Wohlfahrt: Shot Peening and Fatigue of Materials, Proceedings of International Conference on Shot Peening 1, A. Niku-Lari, Ed., Pergamon Press Oxford, pp. 257-262,(1982).

4. J. K. Gregory and L. Wagner: Selective Surface Aging to Improve Fatigue Behavior in a HighStrength Beta Titanium Alloy, Proceedings of 5th International Conference on Fatigue and Fatigue Threshold, EMAS Publishing, England, pp. 177-182 (1993).

5. G. H. Majzoobi, K. Azadikhah and J. Nemati: The effects of deep rolling and shot peening on fretting fatigue resistance of aluminium 7075-T6. Materials Science and Engineering A 516, p. 235-247, (2009).

6. D. W. Hammond and S. A. Meguig: Crack Propagation in the Presence of Shot-peening Residual Stresses, Engineering Fracture Mechanics, 37, pp 387-390 (1990).

7. E. Oberg and R.E. Green: Machinery's Handbook, 25th edition, Industrial Press Inc., New York, (1996).

8. Afshin Manouchehrifar and Kianoush Alasvand: Finite element simulation of deep rolling and evaluate the influence of parameters on residual stress, Recent Researches in Applied Mechanics, p. 121-127, (2009). 